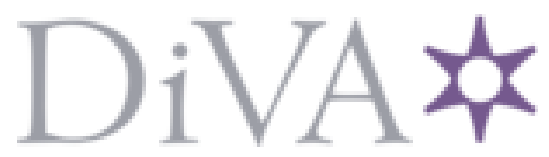

http://www.diva-portal.org

\title{
Postprint
}

This is the accepted version of a paper published in Clinical and Experimental Allergy. This paper has been peer-reviewed but does not include the final publisher proof-corrections or journal pagination.

Citation for the original published paper (version of record):

Eriksson, J., Ekerljung, L., Bossios, A., Bjerg, A., Wennergren, G. et al. (2015)

Aspirin-intolerant asthma in the population: prevalence and important determinants.

Clinical and Experimental Allergy, 45(1): 211-219

http://dx.doi.org/10.1111/cea.12359

Access to the published version may require subscription.

N.B. When citing this work, cite the original published paper.

Permanent link to this version:

http://urn.kb.se/resolve?urn=urn:nbn:se:umu:diva-96072 


\section{Aspirin-intolerant asthma in the population: prevalence and important determinants.}

Jonas Eriksson, MD, PhD (1), Linda Ekerljung, $\mathrm{PhD}$ (1), Apostolos Bossios, MD, PhD (1), Anders Bjerg, MD, PhD (1), Göran Wennergren, MD, PhD (2), Eva Rönmark, PhD (3,4), Kjell Torén, MD, PhD (5), Jan Lötvall, MD, PhD (1) and Bo Lundbäck, MD, PhD (1,3)

Department of Internal Medicine and Clinical Nutrition (1), Department of Paediatrics (2) and Department of Public Health and Community Medicine (5), Sahlgrenska Academy, University of Gothenburg, Gothenburg; The OLIN Studies, Department of Medicine, Sunderby Central Hospital of Norrbotten, Luleå (3), and Department of Public health and Clinical medicine, Department of Medicine, University of Umeå, Umeå (4), Sweden.

Corresponding author: Jonas Eriksson, $\mathrm{MD}, \mathrm{PhD}$

Krefting Research Centre, Box 424

SE - 40530 Gothenburg, Sweden

Phone: +46-703-274729

Fax for correspondence: +46-31-786 6730

E-mail: jonas.eriksson@lungall.gu.se

Running head: Aspirin-intolerant asthma in the population

\section{Funding}

The study was funded by the VBG Group Herman Krefting Foundation for Asthma and Allergy Research. Additional funding was received from the Swedish Heart Lung Foundation, the Swedish Asthma and Allergy Foundation and the Health Authorities of the Västra Götaland Region.

Key words: Aspirin-intolerant asthma, epidemiology, risk factors, obesity, population survey
ABSTRACT
Background: Population-based studies on aspirin-intolerant asthma are very few and no
previous population study has investigated risk factors for the condition.
This article has been accepted for publication and undergone full peer review but has not been through the copyediting, typesetting, pagination and proofreading process, which may lead to differences between this version and the Version of Record. Please cite this article as doi: $10.1111 /$ cea.12359
This article is protected by copyright. All rights reserved. 
Objective: To investigate the prevalence and risk factors of aspirin-intolerant asthma in the general population.

Methods: A questionnaire on respiratory health was mailed to 30000 randomly selected subjects aged 16-75 years in West Sweden, 29218 could be traced and 18087 (62\%) responded. The questionnaire included questions on asthma, respiratory symptoms, aspirininduced dyspnea and possible determinants.

Results: The prevalence of aspirin-intolerant asthma was $0.5 \%, 0.3 \%$ in men and $0.6 \%$ in women $(\mathrm{p}=0.014)$. Sick leave, emergency visits due to asthma and all investigated lower respiratory symptoms were more common in aspirin-intolerant asthma than in aspirin-tolerant asthma. Obesity was a strong risk factor for aspirin-intolerant asthma (BMI>35: OR 12.1; 95\% CI 2.49-58.5) and there was a dose-response relationship between increasing body mass index and risk of aspirin-intolerant asthma. Obesity, airborne occupational exposure and visible mold at home were considerably stronger risk factors for aspirin-intolerant asthma than for aspirin-tolerant asthma. Current smoking was a risk factor for aspirin-intolerant asthma (OR 2.55; 95\% CI 1.47-4.42), but not aspirin-tolerant asthma.

Conclusion: Aspirin-intolerant asthma identified in the general population was associated with a high burden of symptoms, uncontrolled disease and a high morbidity. Increasing body mass index increased the risk of aspirin-intolerant asthma in a dose-response manner. A number of risk factors, including obesity and current smoking, were considerably stronger for aspirin-intolerant asthma than for aspirin-tolerant asthma.

\section{Abbreviations}

AIA Aspirin-intolerant asthma

ATA Aspirin-tolerant asthma

This article is protected by copyright. All rights reserved. 
BHR Bronchial hyperresponsiveness

BMI Body mass index

FeNO Fraction of exhaled nitric oxide

FEV1 Forced expiratory volume in one second

NSAID Non-steroidal anti-inflammatory drug

OR Odds ratio

\section{INTRODUCTION}

Asthma is a common chronic disorder characterized by variable airflow obstruction, bronchial hyperresponsiveness and airway inflammation (1). Asthma is considered a syndrome rather than a single disease entity and thus comprises a number of clinical phenotypes $(2,3)$ as well as underlying biological endotypes (4). A subgroup of asthmatics reacts with airway obstruction upon intake of non-steroidal anti-inflammatory drugs (NSAIDs), frequently referred to as aspirin-intolerant asthma (AIA) (5). Aspirin induced dyspnea was first described in 1922 by Widal et al. (6), but became widely recognized first in the late 1960s as a part of the Samter's triad (7), which comprised aspirin sensitivity, asthma and nasal polyposis.

There are still limited data on the prevalence of AIA in subjects with asthma (8). Very few studies have measured the prevalence of AIA in the general population (9-11) and no previous population study has investigated risk factors for AIA.

Obesity has been identified as an independent risk factor for developing asthma $(12,13)$. Furthermore, obesity has been associated with a severe asthma, therapy resistance, persistent disease and low quality of life in asthmatic subjects $(14,15)$. Severe and therapy resistant asthma has also been associated with aspirin-intolerance $(14,16,17)$. Little is known on the 
relationship between AIA and body mass index (BMI), and this has not been investigated in population-based materials previously.

The aim of this study was to measure the prevalence AIA in the general adult population in West Sweden. Moreover, we sought to investigate the association between a number of risk factors, including obesity and smoking, and AIA.

\section{METHODS}

\section{Study population and methods}

In 2008, a questionnaire on respiratory health was mailed to 30000 inhabitants in West Sweden, aged 16-75 years, of which 18087 (62\%) responded (18). A study of non-response confirmed the representativeness of the study participants (19). The study questionnaire consisted of an extended version of the OLIN questionnaire and the Swedish version of the $\mathrm{GA}^{2} \mathrm{LEN}$ questionnaire and has been previously described in detail (18).

Among responders to the questionnaire, a random selection of 2000 was invited to an extensive clinical examination. In addition, all subjects identified by the questionnaire as having asthma (Definitions, below) were invited. In total, 1052 non-asthmatics and 960 asthmatics agreed to participate, of which 41 were aspirin-intolerant. Examinations included spirometry, methacholine challenge, skin-prick tests (SPT) on a standard panel of 11 aeroallergens, anthropometric measurements, exhaled nitric oxide fraction (FeNO) determination at $50 \mathrm{~mL}^{*} \mathrm{~s}-1$ flow rate, blood samples for assessment of white blood cell differential count and an extensive interview including classification of severity and control of asthma according the Global Initiative for Asthma (GINA) 2006. Detailed description of 
the methods of the clinical examinations is found elsewhere (20). The study was approved by the regional ethics committee of Gothenburg.

\section{Definitions}

Classification of asthma was based on either (i) report of doctor's diagnosis of asthma or (ii) by self-reported ever asthma with at least one of the following conditions during the last 12 months: use of asthma medication, attacks of shortness of breath or any wheeze. Aspirin-induced dyspnea: "Have you ever reacted with dyspnea within three hours after taking a pain killer?" followed by a question on which specific drug that caused the reaction. Subjects specifying a drug not containing acetylsalicylic acid or a NSAID were excluded. Subjects reporting both aspirin-induced dyspnea and asthma were classed as having aspirinintolerant asthma (AIA), while those reporting asthma without aspirin-induced dyspnea were classed as having aspirin-tolerant asthma (ATA). Body mass index (BMI): Weight in kilograms divided by the height in meters squared $\left(\mathrm{kg} \cdot \mathrm{m}^{-2}\right)$. Definitions of the other variables used in the study are available in Table S1 in the Online Supplement.

\section{Analyses}

Statistical analyses were performed using SPSS version 17.0-20.0 (IBM Corp., Somers, NY). Comparisons of proportions were tested with Fisher's exact test. Mantel-Haenszel linear-bylinear association chi-squared test was used for testing for trends. A p-value of $<0.05$ was regarded as statistically significant. Covariates used in the analyses included age, sex, BMI, family history of asthma, smoking habits, water damage at home, visible mold at home, airborne occupational exposure and farm childhood. Three logistic regression models were performed including these variables. First, the odds ratio (OR) for AIA was calculated using non-asthma as reference group; second, ATA was compared with non-asthma; and third, AIA was compared with ATA. All independent variables that had a significant OR in any of the models were included in the multiple logistic regression analyses. ORs were calculated with 
95\% confidence intervals (CI). Characterization of AIA and ATA was based both on questionnaire and clinical data. The observations regarding BMI, waist circumference, allergic sensitization, FEV1\% predicted, BHR, FeNO, neutrophil and eosinophil blood counts, uncontrolled asthma and emergency visits were thus restricted to the smaller clinical sample. Risk factor analyses were mainly based on questionnaire data to obtain maximal statistical power.

\section{RESULTS}

\section{Prevalence and symptoms of AIA}

The prevalence of AIA was $0.5 \%$, which was $39.3 \%$ of subjects with aspirin-induced dyspnea (Table 1). In subjects with aspirin-induced dyspnea without a diagnosis of asthma, only $32 \%$ reported occasional wheeze and $16 \%$ attacks of shortness of breath. Women had a significantly higher prevalence of AIA than men (0.6 vs. $0.3 \%, \mathrm{p}=0.014)$. AIA was most common $(0.7 \%)$ in ages 36-55 years, while the prevalence of ATA was highest in ages 16-35 years $(10.8 \%)$ and decreased with age $(\mathrm{p}<0.001)$. Subjects with AIA comprised $5.1 \%$ of subjects with asthma. All investigated respiratory symptoms, except allergic rhinitis, were more common in AIA than in ATA (Figure 1). Whereas the prevalence of allergic rhinitis was similar in AIA and ATA, chronic rhinosinusitis was noticeably more common in AIA than in ATA (43.2 vs. 18.2\%, p<0.001). Detailed numerical values are available in Table S2 in the Online Supplement. A considerably higher proportion of subjects with AIA reported multiple symptoms of asthma compared to subjects with ATA (Figure 2). In AIA, 40.9\% reported all four investigated symptoms versus $21.0 \%$ in ATA $(\mathrm{p}<0.001)$.

\section{Distribution of background variables}

Mean BMI was higher in AIA than in ATA, both when based on self-reported data (27.6 vs. 25.9, $\mathrm{p}=0.002$ ) and objective height and weight measurements (29.7 vs. 27.1, $\mathrm{p}=0.001)$ (Table 
2). Several exposures were significantly more common in AIA than in ATA. This was particularly true for current smoking $(34.5$ vs. $16.2 \%, \mathrm{p}<0.001)$ and visible mold at home (24.1 vs. $11.1 \%, \mathrm{p}<0.001)$.

\section{Clinical characteristics and morbidity}

Allergic sensitization was equally common in AIA and ATA (Table 3). Moreover, there were no statistically significant differences in bronchial hyperresponsiveness, FEV1 \% predicted and blood eosinophils between AIA and ATA. Neutrophils in blood was significantly higher in $\operatorname{AIA}\left(4.510^{9} / \mathrm{L}\right)$ compared to ATA $\left(3.810^{9} / \mathrm{L}\right)$ and non-asthma $\left(3.710^{9} / \mathrm{L}\right), \mathrm{p}=0.009$ and p $<0.001$ respectively. FeNO was lower in AIA compared to ATA (17.9 vs. 25.4 ppb, $\mathrm{p}=0.042)$ (Table 3).

Uncontrolled disease (GINA 2006) was substantially more common in AIA than in ATA (26.7 vs. $11.2 \%, \mathrm{p}=0.018$ ). In addition, a number or morbidity variables were more common in AIA than in ATA (Table 3). A higher proportion of subjects with AIA reported current use of asthma medication and emergency visits due to breathing problems than subjects with ATA. Further, overall sick leave, sick leave due to breathing problems and having changed occupation because of asthma was more common in AIA than in ATA.

\section{Risk factors for aspirin-intolerant asthma}

The prevalence of AIA increased markedly with increasing BMI (Figure 3). In subjects with a BMI of 35 or higher, prevalence of AIA was $2.2 \%$ as compared to $0.3-0.4 \%$ in subjects with BMI <30. This trend remained when the analysis was limited to non-smokers, but the overall prevalence was lower. Furthermore, the association with BMI was found both in ages 16-45 years and in ages $46-75$ years. When stratifying the analysis by sex, the trend was found to be strong in women, while significance was not reached in men (data not shown). Further investigation of gender specific differences in relation to AIA was not feasible due to insufficient statistical power.

This article is protected by copyright. All rights reserved. 
Univariate logistic regression analysis was performed on a number of possible risk factors for AIA and ATA, respectively (see Table S3 in the Online Supplement). All variables that were significantly associated with either AIA or ATA in the univariate analysis were included in the multivariate analysis (Table 4). Obesity was found to be strongly independently associated with AIA compared to non-asthma in the multivariate analysis. BMI $\geq 35$ yielded an OR of 12.07 (95\% CI 2.49-58.5) and BMI 30-35 yielded an OR of 7.31 (95\% CI 1.6332.8). Other significant risk factors for AIA were airborne occupational exposure (OR 2.8), visible mold at home (OR 2.6), current smoking (OR 2.6), ex-smoking (OR 2.1), female sex (OR 2.3) and family history of asthma (OR 2.1). When adding chronic rhinosinusitis to the model the condition was found to be strongly associated (OR 7.6), while the other variables were only marginally affected.

When ATA was used as a reference category, statistically significant risk factors for AIA were $\mathrm{BMI}>35$ (OR 6.40; 1.27-32.2), chronic rhinosinusitis (OR 2.85; 1.73-4.70), current smoking (OR 2.65; 1.49-4.71), ex-smoking (OR 1.82; 1.01-3.28), visible mold at home (OR $2.12 ; 1.13-3.96)$ and airborne occupational exposure (OR 2.09; 1.28-3.41), while allergic rhinitis, female sex and family history of asthma no longer appeared as significant risk factors.

\section{DISCUSSION}

We found a prevalence of AIA of $0.5 \%$, which is consistent with findings from previous population-based studies (9-11), thus confirming the external validity of our study. Being the first population study to perform a comprehensive risk factor analysis of AIA, we found obesity as well as a number of environmental exposures to be associated with the disease. The risk factor pattern of AIA differed considerably from that of ATA as various risk factors were unique or considerably stronger for AIA. The most important risk factor was increasing 
BMI which increased the risk of AIA in a dose-response manner independently of a number of potential confounders.

Although a number of studies of asthma patients have sought to measure the prevalence of AIA (8), population-based studies on AIA are very few (9-11). A Polish study reported a prevalence of AIA of $0.6 \%$ (9), which is highly consistent with our findings. A survey conducted in Finland (11) found a prevalence of aspirin-intolerant breathlessness regardless of asthma of $1.2 \%$, which is identical to our result. Furthermore, as a part of a larger Australian study, mainly based on asthma patients (10), the prevalence of AIA was measured also in a small population-based sample. In the population-based sample, prevalence of AIA among asthmatics was found to be $10.9 \%$, which corresponded to $1.1 \%$ of the total population. The substantially higher prevalence of AIA reported by this study is in accordance with a generally higher prevalence of asthma and wheeze in Australia compared with many countries in northern Europe including Sweden, Finland and Poland (1).

Several studies have investigated the association between asthma and obesity (12-15). Obesity has been associated with development of asthma $(12,13)$ as well as with a high severity of asthma $(15,21)$. Furthermore, the European ENFUMOSA study identified aspirin sensitivity, sinusitis and obesity in women as being associated with a severe phenotype of asthma (14). Only one study has investigated the association between obesity and aspirinintolerant asthma (22). In contrast to our findings, this clinical study conducted in South Korea found no significant difference in BMI between patients with AIA and patients with ATA. However, this study defined obesity as a BMI exceeding the 95th percentile of the controls and not according to the World Health Organization (WHO) classification. Owing to lower prevalence of obesity in Korea compared to Sweden $(23,24)$, the Korean study probably contained very few severely obese $(\mathrm{BMI} \geq 35)$ subjects, which was the group that was found to be significantly associated with aspirin-intolerance in our study.

This article is protected by copyright. All rights reserved. 
Our finding of a significantly higher blood neutrophil count in AIA compared to ATA and non-asthmatics, respectively, is in line with a recent British study that found increased neutrophils in the bronchial mucosa in AIA compared to ATA (25). Furthermore, a Korean study found increased levels of neutrophil activation markers in serum in aspirin-induced urticaria compared to healthy controls, arguing for a role of neutrophils in systemic inflammation as well (26). Systemic inflammation may indeed be the pathophysiological mechanism behind the correlation between obesity and AIA (27). Adipose tissue from obese individuals produce inflammatory cytokines as well as adipokines such as leptin and adiponectin (28). Leptin, which is increased in proportion to BMI and correlates with lipid status (29), has been found to induce bronchial hyperresponsiveness and elevated serum $\operatorname{IgE}$ levels when administered in a murine model (30). Adiponectin, which decreases with increasing visceral obesity, has been found to inhibit pro-inflammatory cytokines as well as to induce anti-inflammatory cytokines (31). In addition, there was a weak but significant cross-correlation between BMI and blood neutrophil count in our study (Figure S1).

In contrast to the association between AIA and eosinophilia found in some studies, levels of blood eosinophil counts were similar in AIA and ATA in our study. This may partly be explained by a higher use of inhaled corticosteroids in AIA than in ATA according to data from the clinical examination.

Elevated levels of leukotrienes is supposed to be a key feature in the pathogenesis of AIA (32). Thus, the findings of a correlation between BMI and granulocyte generation of leukotriene C4 (33), and an association between obesity and increased urinary leukotriene E4 in asthmatic patients (34), provide support for the hypothesis that obesity may be involved in the development of AIA.

Apart from BMI, we found that AIA differed from ATA in several aspects including gender composition, smoking habits, occupational status and exposure to various environmental 
factors. In order to adjust for confounding potentially inflicted by such differences, multiple logistic regression analyses were performed for both AIA and ATA. Both AIA and ATA were confirmed as being significantly associated with obesity. However, when comparing AIA with ATA, the association with obesity was found to be considerably stronger for AIA than for ATA.

Previous studies have found a higher risk of AIA in subjects with allergy and nasal polyposis, respectively $(10,11)$. Bochenek et al. found that atopy was more frequent in patients with intolerance to NSAIDs than in controls (35), Valley et al. found that atopy was associated with an increased risk of AIA (10) and Hedman et al. found a 8 times higher risk of aspirin intolerant dyspnea in subjects with allergic rhinitis than in those without (11). We found that allergic rhinitis was indeed strongly associated with both AIA and ATA. However, odds ratios were similar for the two conditions, suggesting that aspirin-intolerance and allergy are separate processes in the development and maintenance of asthma $(7,16)$.

The importance of environmental exposures for the development of asthma is well documented (36). We found that current and former smoking, airborne occupational exposures and visible mold at home were associated with an increased risk of AIA. An American clinical study also found an association between AIA and smoking (37). Although some risk factors were shared between AIA and ATA, the risk factor patterns differed widely, suggesting a diverse pathophysiology of these two asthma phenotypes $(16,32)$.

Severity of asthma is difficult to measure in epidemiologic studies. However, the burden of respiratory symptoms may serve as a proxy for disease severity (20). We found a higher prevalence of a large number of respiratory symptoms in AIA than in ATA. Furthermore, having multiple symptoms common in asthma was markedly more common in AIA than in ATA. These findings suggest a higher disease severity in AIA as compared with ATA, which is in agreement with results from clinical studies (38). Moreover, we found that uncontrolled 
asthma, emergency visits and sick leave due to breathing problems and changing work due to asthma were all more than twice as common in AIA than in ATA. These data suggest that AIA is associated with high morbidity, thus causing a substantial burden both on the sufferers and the society.

The current study benefits from its population-based design, large sample size and the use of well validated questions. The study is the largest population-based study on AIA to date (i.e. 18087 vs. 12971 Kasper et al. (9), 4300 Hedman et al. (11) and 1298 Valley et al. (10)). The response rate $(62 \%)$ is comparable to other recent European studies and a study of nonresponse confirmed the participants as being highly representative for the population in the studied area (19). The association between AIA and BMI was preserved when BMI was based on measured height and weight in the clinically examined subsample, which confirms the validity of our results. Overall BMI was higher when based on measured height and weight than when based on self-reported data. This may be explained by the fact that subjects were weighed with indoor clothing in the clinic. Another possibility is underestimation of self-reported weight, which would however not lead to an overestimation of the association with AIA. There are no published results verifying aspirin-intolerance by provocation tests on population-based data. However, in a clinical study, history of aspirin hypersensitivity in asthmatic patients yielded a positive predictive value of $57 \%$ for AIA defined as a positive oral provocation test (39). Confirmation of aspirin intolerance by oral or inhaled aspirin provocations would have strengthened our results further. However, we did not receive approval for aspirin challenges by the regional ethics committee. Instead, the questionnaire variable on AIA was validated by telephone interviews. Among the 41 subjects with AIA that participated in the clinical examinations, telephone numbers were available for 39. Among these, $27(69 \%)$ could be reached and agreed to participate, among whom AIA was confirmed in $19(70 \%)$. Avoidance of aspirin and NSAID in certain subjects may have left some cases 
of AIA unrecognized. However, major underdiagnosis is not probable since these drugs are widely used in the studied area. Among older smokers with asthma, some may also meet the criteria for COPD. However, it is not probable that misclassification with COPD biased our results in any major way since the association between AIA and obesity was found also when limiting the analysis to ages 16-45 years. Furthermore, since symptoms of asthma were uncommon among subjects with aspirin-induced dyspnea without asthma, the large majority in this group is not likely to have asthma. It is further unlikely that use of oral corticosteroids confounded the association between obesity and AIA since no subject with AIA used oral corticosteroids on a regular basis (data from the clinical examination).

In conclusion, as the first population based study specifically addressing risk factors for AIA, we found that obesity as well as a number of environmental exposures, including current smoking and visible mold at home, was strongly associated with the disease. The strong positive association of AIA to increasing BMI was independent of other risk factors and potential confounders. The stronger association with obesity in AIA compared to in ATA may be related to systemic inflammation with a neutrophil component.

\section{ACKNOWLEDGMENTS}

We thank the research team at the Krefting Research Centre, especially Lotte Edvardsson, Maria Falkdal, Helen Friberg, Anna Merlander, MaryAnne Raneklint and Helén Törnqvist, for the collection of data. We also thank associate professor Barbro Dahlén at the Karolinska Institute, Stockholm, Sweden, for sharing valuable insights and comments regarding aspirinintolerant asthma.

This article is protected by copyright. All rights reserved. 


\section{CONFLICT OF INTEREST}

The authors declare that there are no conflicts of interest.

\section{REFERENCES}

1. $\quad$ Eder W, Ege MJ, von Mutius E. The asthma epidemic. $N$ Engl J Med 2006; 355:2226-35.

2. Wenzel SE. Asthma: defining of the persistent adult phenotypes. Lancet 2006; 368:804-13.

3. Carolan BJ, Sutherland ER. Clinical phenotypes of chronic obstructive pulmonary disease and asthma: recent advances. J Allergy Clin Immunol 2013; 131:627-34.

4. Lötvall J, Akdis CA, Bacharier LB, Bjermer L, Casale TB, Custovic A, et al. Asthma endotypes: a new approach to classification of disease entities within the asthma syndrome. J Allergy Clin Immunol 2011; 127:355-60.

5. Sanak M, Gielicz A, Bochenek G, Kaszuba M, Nizankowska-Mogilnicka E, Szczeklik A. Targeted eicosanoid lipidomics of exhaled breath condensate provide a distinct pattern in the aspirin-intolerant asthma phenotype. J Allergy Clin Immunol 2011; 127:1141-7.

6. Widal M, Abrami P, Lermeyez J. Anaphylaxie et idiosyncrasie. Presse Med 1922; 30:189-93.

7. Samter M, Beers RF, Jr. Intolerance to aspirin. Clinical studies and consideration of its pathogenesis. Ann Intern Med 1968; 68:975-83.

8. Jenkins C, Costello J, Hodge L. Systematic review of prevalence of aspirin induced asthma and its implications for clinical practice. BMJ 2004; 328:434.

This article is protected by copyright. All rights reserved. 
9.

Kasper L, Sladek K, Duplaga M, Bochenek G, Liebhart J, Gladysz U, et al.

Prevalence of asthma with aspirin hypersensitivity in the adult population of Poland. Allergy 2003; 58:1064-6.

10. Vally H, Taylor ML, Thompson PJ. The prevalence of aspirin intolerant asthma (AIA) in Australian asthmatic patients. Thorax 2002; 57:569-74.

11. Hedman J, Kaprio J, Poussa T, Nieminen MM. Prevalence of asthma, aspirin intolerance, nasal polyposis and chronic obstructive pulmonary disease in a population-based study. Int J Epidemiol 1999; 28:717-22.

12. Rönmark E, Andersson C, Nyström L, Forsberg B, Järvholm B, Lundbäck B. Obesity increases the risk of incident asthma among adults. Eur Respir J 2005; 25:282-8.

13. Ford ES. The epidemiology of obesity and asthma. J Allergy Clin Immunol 2005; 115:897-909.

14. Wenzel SE, Busse WW. Severe asthma: lessons from the Severe Asthma Research Program. J Allergy Clin Immunol 2007; 119:14-21.

15. Mosen DM, Schatz M, Magid DJ, Camargo CA, Jr. The relationship between obesity and asthma severity and control in adults. J Allergy Clin Immunol 2008; 122:507-11.

16. Szczeklik A, Nizankowska E, Duplaga M. Natural history of aspirin-induced asthma. AIANE Investigators. European Network on Aspirin-Induced Asthma. Eur Respir J 2000; 16:432-6.

17. Fukutomi Y, Nakamura H, Kobayashi F, Taniguchi M, Konno S, Nishimura M, et al. Nationwide cross-sectional population-based study on the prevalences of asthma and asthma symptoms among Japanese adults. Int Arch Allergy Immunol 2010; 153:280-7.

18. Lötvall J, Ekerljung L, Rönmark EP, Wennergren G, Lindén A, Rönmark E, et al. West Sweden Asthma Study: prevalence trends over the last 18 years argues no recent increase in asthma. Respir Res 2009; 10:94.

This article is protected by copyright. All rights reserved. 
19. Rönmark EP, Ekerljung L, Lötvall J, Torén K, Rönmark E, Lundbäck B. Large scale questionnaire survey on respiratory health in Sweden: effects of late- and non-response. Respir Med 2009; 103:1807-15.

20. Ekerljung L, Bossios A, Lötvall J, Olin AC, Rönmark E, Wennergren G, et al. Multi-symptom asthma as an indication of disease severity in epidemiology. Eur Respir $J$ $2011 ; 38: 825-32$.

21. The ENFUMOSA cross-sectional European multicentre study of the clinical phenotype of chronic severe asthma. European Network for Understanding Mechanisms of Severe Asthma. Eur Respir J 2003; 22:470-7.

22. Jang AS, Park JS, Park SW, Kim DJ, Uh ST, Seo KH, et al. Obesity in aspirintolerant and aspirin-intolerant asthmatics. Respirology 2008; 13:1034-8.

23. Kim DM, Ahn CW, Nam SY. Prevalence of obesity in Korea. Obes Rev 2005; 6:117-21.

24. Neovius M, Janson A, Rössner S. Prevalence of obesity in Sweden. Obes Rev 2006; 7:1-3.

25. Corrigan CJ, Napoli RL, Meng Q, Fang C, Wu H, Tochiki K, et al. Reduced expression of the prostaglandin E2 receptor E-prostanoid 2 on bronchial mucosal leukocytes in patients with aspirin-sensitive asthma. J Allergy Clin Immunol 2012; 129:1636-46.

26. Choi SJ, Ye YM, Hur GY, Shin SY, Han JH, Park HS. Neutrophil activation in patients with ASA-induced urticaria. J Clin Immunol 2008; 28:244-9.

27. Shore SA. Obesity and asthma: possible mechanisms. J Allergy Clin Immunol 2008; 121:1087-93.

28. Beuther DA, Weiss ST, Sutherland ER. Obesity and asthma. Am J Respir Crit Care Med 2006; 174:112-9.

This article is protected by copyright. All rights reserved. 
al. Relation of serum leptin levels to lipid profile in healthy children. Metabolism 2001; 50:1091-4.

30.

Shore SA, Schwartzman IN, Mellema MS, Flynt L, Imrich A, Johnston RA. Effect of leptin on allergic airway responses in mice. J Allergy Clin Immunol 2005; 115:1039.

31. Lugogo NL, Kraft M, Dixon AE. Does obesity produce a distinct asthma phenotype? J Appl Physiol 2010; 108:729-34.

32. Szczeklik A, Stevenson DD. Aspirin-induced asthma: advances in pathogenesis, diagnosis, and management. J Allergy Clin Immunol 2003; 111:913-21.

33. Cederholm T, Lindgren JA, Palmblad J. Impaired leukotriene C4 generation in granulocytes from protein-energy malnourished chronically ill elderly. J Intern Med 2000; 247:715-22.

34. Giouleka P, Papatheodorou G, Lyberopoulos P, Karakatsani A, Alchanatis M, Roussos C, et al. Body mass index is associated with leukotriene inflammation in asthmatics. Eur J Clin Invest 2011; 41:30-8.

35. Bochenek G, Nizankowska E, Szczeklik A. The atopy trait in hypersensitivity to nonsteroidal anti-inflammatory drugs. Allergy 1996; 51:16-23.

36. Peden DB, Bush RK. Advances in environmental and occupational disorders in 2012. J Allergy Clin Immunol 2013; 131:668-74.

37. Chang JE, Ding D, Martin-Lazaro J, White A, Stevenson DD. Smoking, environmental tobacco smoke, and aspirin-exacerbated respiratory disease. Ann Allergy Asthma Immunol 2012; 108:14-9.

This article is protected by copyright. All rights reserved. 
38. Mascia K, Haselkorn T, Deniz YM, Miller DP, Bleecker ER, Borish L. Aspirin sensitivity and severity of asthma: evidence for irreversible airway obstruction in patients with severe or difficult-to-treat asthma. J Allergy Clin Immunol 2005; 116:970-5.

39. Chang HS, Park JS, Jang AS, Park SW, Uh ST, Kim YH, et al. Diagnostic

Value of Clinical Parameters in the Prediction of Aspirin-Exacerbated Respiratory Disease in Asthma. Allergy Asthma Immunol Res 2011; 3:256-264.

\section{TABLES}

Table 1. Prevalence (\%) of aspirin-intolerant asthma (AIA) and aspirin-tolerant asthma (ATA) by age and sex.

\begin{tabular}{lllllll} 
& & & AIA & p-value & ATA & p-value* $^{*}$ All ages: \\
& total & $n=18087$ & 0.5 & & 9.1 & \\
& men & $n=8190$ & 0.3 & & 8.2 & \\
& women & $n=9897$ & 0.6 & 0.014 & 9.8 & $<0.001$ \\
16-35 years: & total & $n=5723$ & 0.4 & & 10.8 & \\
& men & $n=2471$ & 0.3 & 0.53 & 10.6 & \multirow{2}{*}{0.76} \\
& women & $n=3252$ & 0.5 & & 10.9 & \\
36-55 years: & total & $n=6515$ & 0.7 & & 8.7 & \\
& men & $n=2958$ & 0.4 & 0.021 & 7.6 & \multirow{2}{*}{0.008} \\
& women & $n=3557$ & 0.9 & & 9.5 & \\
56-75 years: & total & $n=5849$ & 0.4 & & 7.8 & \\
& men & $n=2761$ & 0.3 & 0.39 & 6.5 & \multirow{2}{*}{0.001}
\end{tabular}

*: Difference by sex (Fisher's exact test, two-sided) 
Table 2. Demographics for subjects with aspirin-intolerant asthma (AIA), aspirin-tolerant asthma (ATA) and non-asthma.

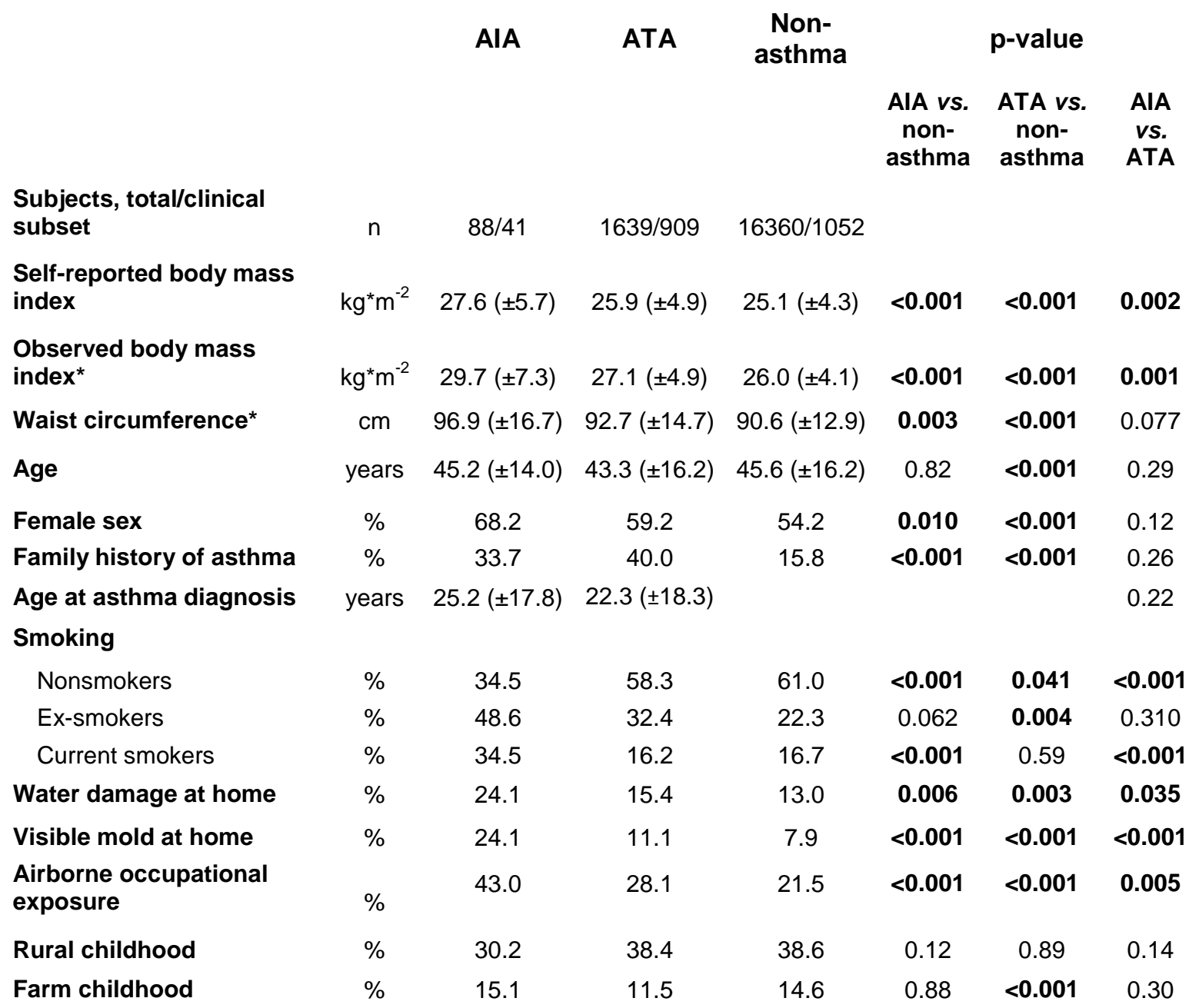

Data are presented as mean $( \pm \mathrm{SD})$ or \%. Bold indicates statistically significant differences. *: clinically examined subset.

This article is protected by copyright. All rights reserved. 
Table 3. Characterization of aspirin-intolerant asthma (AIA), aspirin-tolerant asthma (ATA) and non-asthma based on clinical and morbidity variables.

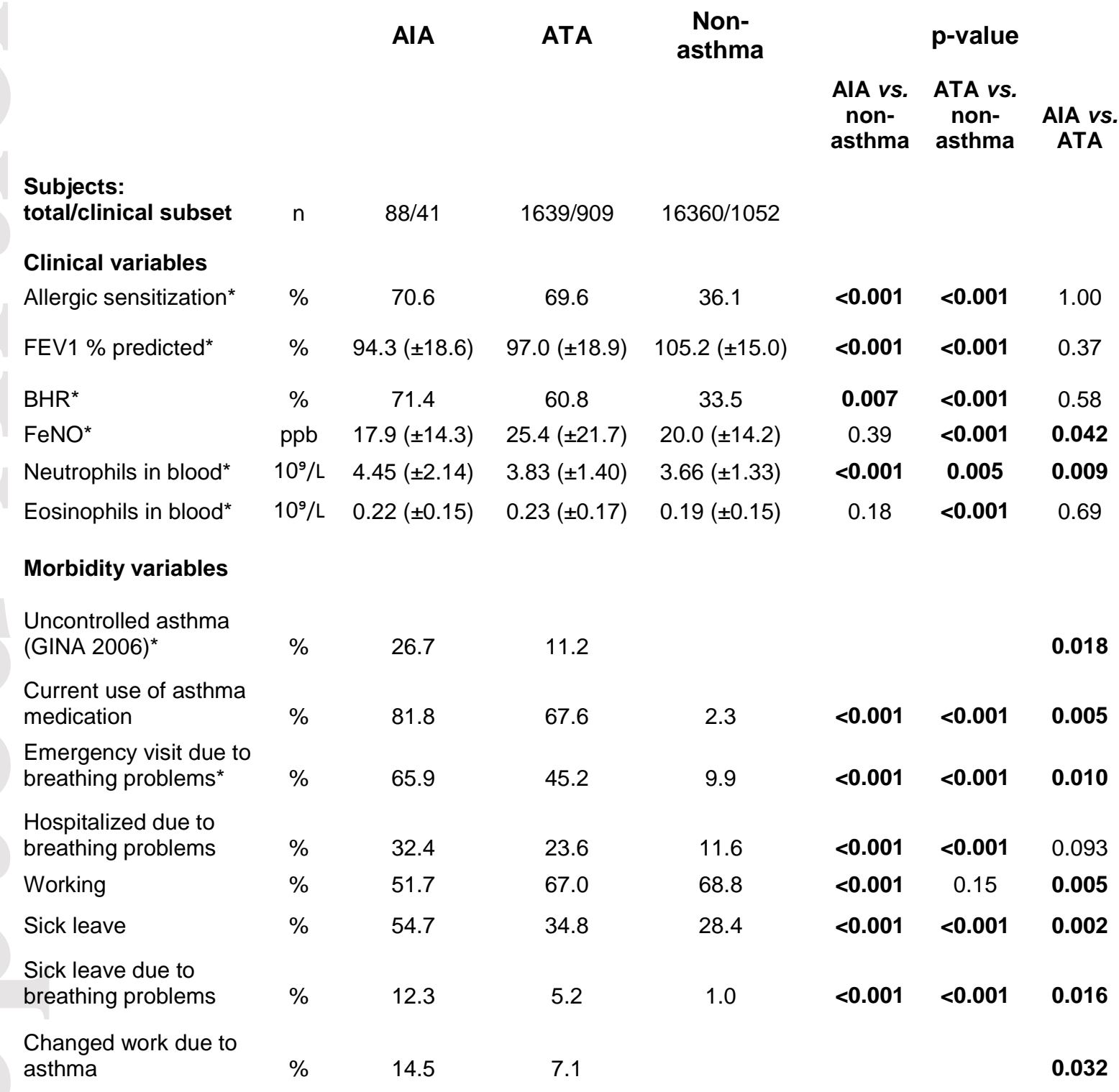

Data are presented as mean $( \pm S D)$ or $\%$ unless otherwise stated. Bold indicates statistically significant differences. *: clinically examined subset. BHR: Bronchial hyperresponsiveness.

This article is protected by copyright. All rights reserved. 
Table 4. Risk factors (OR 95\% Cl) for aspirin-intolerant asthma (AIA) and aspirin-tolerant asthma (ATA) by multivariate logistic regression analysis. Independent variables were obtained from the participants in the questionnaire ( $n=18087)$.

Independent variables

Female gender

Body mass index

Age

Family history of asthma

Smoking

Airborne occupational exposure

Visible mold at home

Water damage at home

Farm childhood

\section{Dependent variables}

AIA vs. non-asthma ATA vs. non-asthma

OR $(95 \% \mathrm{Cl})$

OR $(95 \% \mathrm{Cl})$

AIA vs. ATA

OR $(95 \% \mathrm{Cl})$

2.30 (1.39-3.82)

$\leq 20$

$>20 \leq 25$

$>25 \leq 30$

$>30 \leq 35$

$>35$

16-35 years

36-55 years

56-75 years

1
$2.59(0.61-10.99)$
$2.67(0.61-11.75)$
$\mathbf{7 . 3 1}(\mathbf{1 . 6 3 - 3 2 . 8 )}$
$\mathbf{1 2 . 0 7 ( 2 . 4 9 - 5 8 . 5 )}$

1

$1.13(0.65-1.94)$

$0.70(0.36-1.35)$

$1.23(1.09-1.38)$

$1.59(0.94-2.68)$

$0.95(0.76-1.18)$

$1.14(0.91-1.44)$

$1.63(1.25-2.12)$

$1.85(1.31-2.62)$

1

$\mathbf{0 . 7 4}(\mathbf{0 . 6 5 - 0 . 8 5 )} \quad 1.25(0.70-2.23)$

$0.69(0.60-0.80) \quad 0.75(0.38-1.49)$

2.14 (1.31-3.49)

1

2.13 (1.21-3.76)

2.55 (1.47-4.42)

3.37 (3.01-3.77)

0.65 (0.39-1.08)

Non-smoker

Ex-smoker

Current

smoker

2.77 (1.72-4.48)

1.38 (1.22-1.57)

2.09 (1.28-3.41)

2.63 (1.45-4.74)

1.31 (1.08-1.57)

2.12 (1.13-3.96)

1.54 (0.87-2.73)

$1.08(0.92-1.27)$

1.31 (0.71-2.39)

$1.10(0.59-2.08)$

$0.76(0.64-0.90)$

$1.60(0.82-3.13)$

Odds ratios were adjusted for all independent variables presented. Bold indicates statistically significant associations.

This article is protected by copyright. All rights reserved. 


\section{FIGURE LEGENDS}

Figure 1. Prevalence of respiratory symptoms and conditions in aspirin-tolerant asthma (blue bars) vs. aspirin-intolerant asthma (red bars). SOB: shortness of breath. P-values by two sided Fisher's exact test. *: $\mathrm{p}<0.05 . \dagger: \mathrm{p}<0.001$.

Figure 2. Presence of current asthma medication and common asthma symptoms in aspirintolerant asthma vs. aspirin-intolerant asthma. Symptoms were: attacks of shortness of breath, recurrent wheeze and at least one out of dyspnea, breathlessness at exertion, breathlessness at cold and breathlessness at exertion in cold. P-values by two sided Fisher's exact test.

Figure 3. Prevalence of aspirin-intolerant asthma by body mass index. P-value for trend was calculated by Mantel-Haenszel chi squared test.

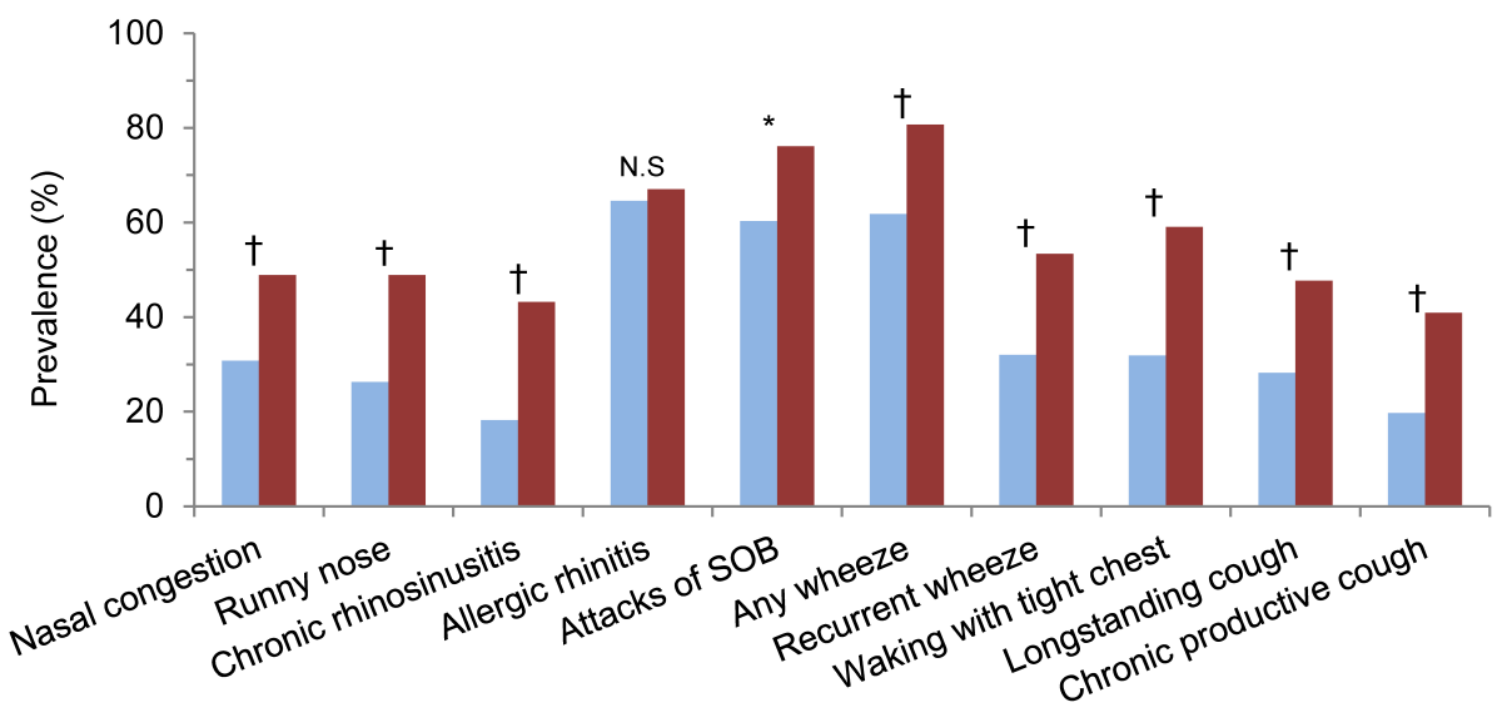

This article is protected by copyright. All rights reserved. 

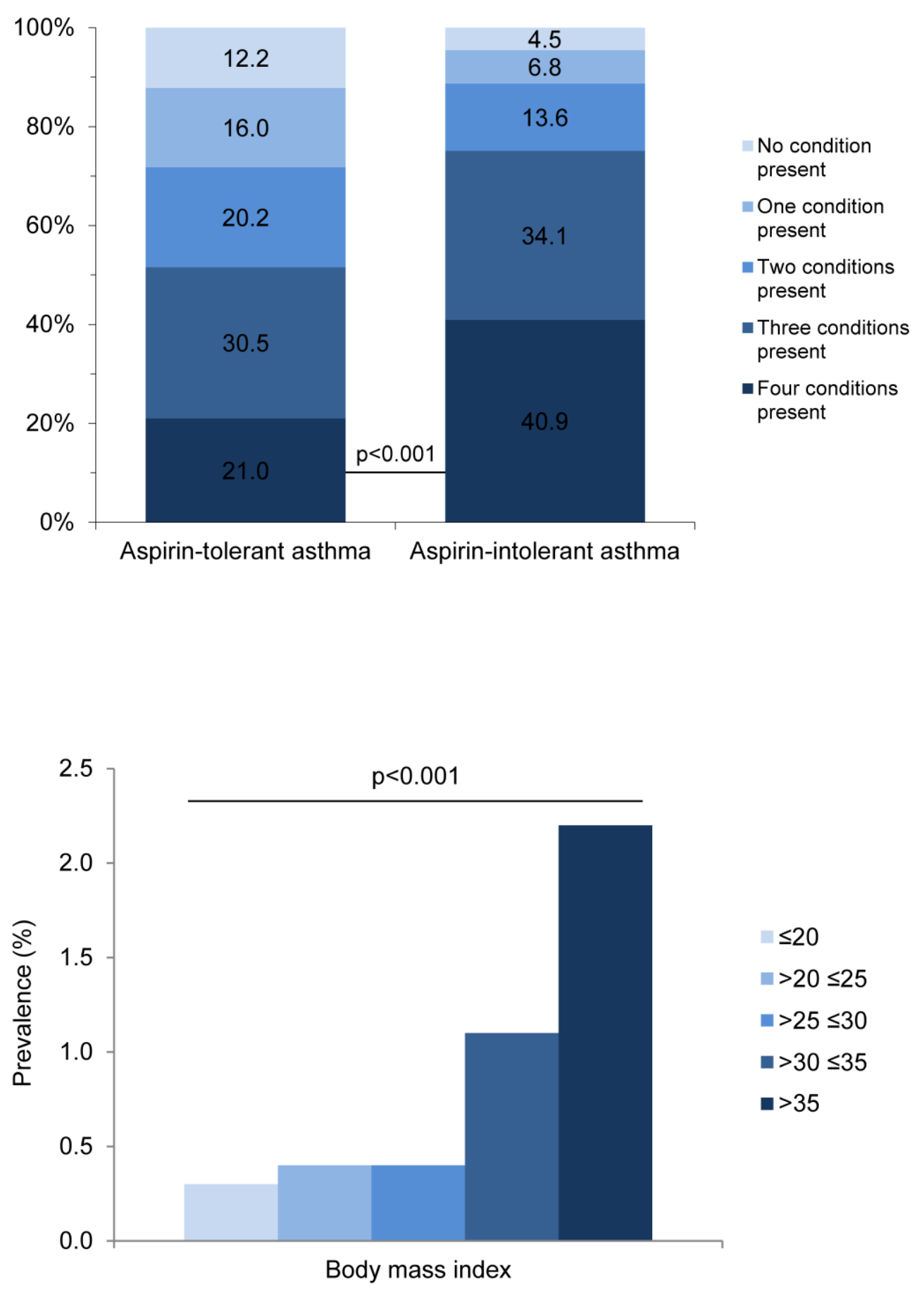

This article is protected by copyright. All rights reserved. 